\title{
What's going on here? Deconstructing the interactive encounter.
}

Janice P Burke

Thomas Jefferson University

Follow this and additional works at: https://jdc.jefferson.edu/otfp

Part of the Occupational Therapy Commons

Let us know how access to this document benefits you

\section{Recommended Citation}

Burke, Janice P, "What's going on here? Deconstructing the interactive encounter." (2010).

Department of Occupational Therapy Faculty Papers. Paper 54.

https://jdc.jefferson.edu/otfp/54

This Article is brought to you for free and open access by the Jefferson Digital Commons. The Jefferson Digital Commons is a service of Thomas Jefferson University's Center for Teaching and Learning (CTL). The Commons is a showcase for Jefferson books and journals, peer-reviewed scholarly publications, unique historical collections from the University archives, and teaching tools. The Jefferson Digital Commons allows researchers and interested readers anywhere in the world to learn about and keep up to date with Jefferson scholarship. This article has been accepted for inclusion in Department of Occupational Therapy Faculty Papers by an authorized administrator of the Jefferson Digital Commons. For more information, please contact: JeffersonDigitalCommons@jefferson.edu. 


\section{Eleanor Clarke Slagle Lecture}

\section{What's Going on Here? Deconstructing the Interactive Encounter}

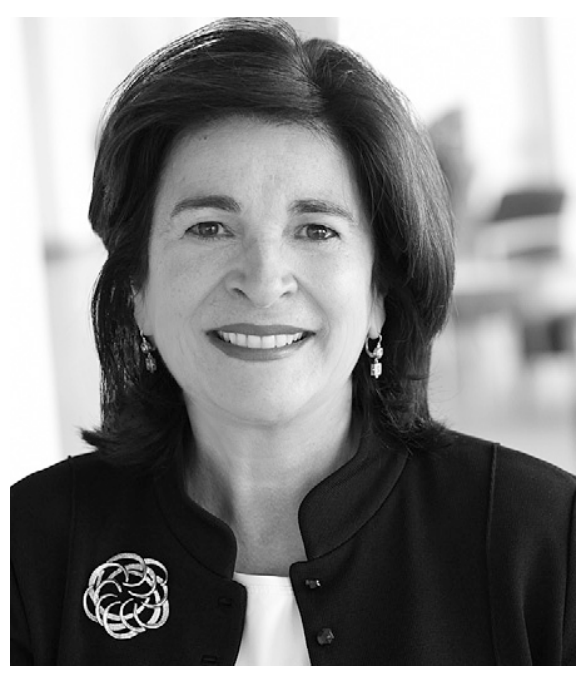

Janice Posatery Burke, PhD, OTR/L, FAOTA
Janice Posatery Burke, PhD, OTR/L, FAOTA, is Professor and Chair, Department of Occupational Therapy, Dean, Jefferson School of Health Professions, Thomas Jefferson University, 130 South Ninth Street, Philadelphia, PA 19107; Janice.burke@jefferson.edu
Burke, J. P. (2010). What's going on here? Deconstructing the interactive encounter (Eleanor Clarke Slagle Lecture). American Journal of Occupational Therapy, 64, 855-868. doi: 10.5014/ajot.2010.64604

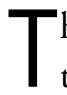

he Slagle gave me an unprecedented opportunity to read and savor many of the great thoughts of my predecessors. They are the leaders of our field and an impressive group of thinkers. I am grateful for the opportunity I spent this past year with their work.

I have often sought to understand our leaders and their drive for success and passion for our field. They climbed a century-high mountain and obtained a towering history of creativity and clinical excellence. The excitement and enthusiasm of those wise individuals who created our profession gave us our foundation, and I am sure their passion represents the push that got many of us into occupational therapy and here this evening.

As they expressed their hopes for occupational therapy, they set a very high standard for success and challenged us to do our best for the profession. They often sought what seemed to be unachievable heights and made us all dream. They are very hard acts to follow.

I viewed the honor of working on the Slagle as an intellectual expedition. This past year, I set out on a journey to reach the base camp established by those who came before. I wanted to expand my thinking and seek a path that would enhance my sphere of knowledge about our profession. The expedition quickly became a catalyst for me to seek in-depth information about ideas that I would not normally have had the time to explore as I worked on my desire to find a new way of "knowing" the experience we call occupational therapy.

Like the peak of a distant mountain, the long hike often seemed too great a distance to travel, too high a step to reach, or simply too far in the future to be real. My colleagues, friends, and family helped make the journey enjoyable. They softened the bumps on the road; straightened the many hairpin turns that threatened the expedition; and comforted me with good conversation, insightful thoughts, and exceptional counsel. My work tonight reflects the culmination and synthesis of all who have helped me. Because of them, I know that what I present tonight is not just mine. I am very thankful for their support.

\section{Scope of the Talk}

As I worked on this presentation, I realized the importance of the journey. This past year, I had the chance to forge a new path to information that resides outside the commonplace of occupational therapy. I worked to clear a trail that will more fully explain the interactional space and interpersonal relations that occupational therapists create during the occupational therapy encounter. 
I can trace my deep interest in the idea of interaction to my early experiences as a young clinician. During those first years, I worked in different settings: a rehabilitation center, an outpatient clinic, and schools with both adults and children. In those treatment environments, I wondered why it was that some therapy sessions felt so very different from others. I began to consider how a therapist (me) could deliberately shape the treatment session to promote its "success." Simply put, I wanted to know more about why certain human interactions in therapy worked. I wanted to discover the secret of success as a clinician and define ways to replicate that success time and time again.

I had further glimpses of this goal when I was working on my master's degree at the University of Southern California (USC), creating a model of occupational behavior that included personal causation, role, and socialization and later while defining the Model of Human Occupation. I moved further along when I taught in a clinical faculty position at USC.

Those brief moments of clarity helped inform my work as I established my first private practice, Therapy West in Los Angeles, and later, when I moved to Thomas Jefferson University in Philadelphia. My objectives matured as I worked full time with university students as well as in my small private practice with young children and their families and while I finished my dissertation and doctorate. The ephemeral emergence of interaction I observed and reflected on became more lasting and permanent as I became a seasoned therapist and educator and shaped the first independent research I did as I observed clinicians in action.

To this day, every time I observe or step inside the clinical interaction, I ask myself, What more can I see here? What are the nonverbal interactions that help or hinder this therapy? How are others reacting to my words and actions? The answers collected over the years inform my talk today.

\section{Passion for Interaction}

I have a passion for interaction. The conduct of an interaction is endlessly fascinating. It's a riddle. It is always different, yet it includes the same parts and structure each time (beginning, middle, end). It can be new but also has an old familiarity. It can happen over a long period of time (as in an hour-long team meeting) or very quickly (during a short elevator ride or a walk down a corridor). It has a physical quality (where you are in relation to another), but it does not require touch. It may have visual features (eye contact, a common point of focus) and even sound, but neither is essential. It happens in starched, formal settings as well as in relaxed, informal ones.
My initial observation of and later fascination with people-to-people interaction came about because of my family (always a good target for blame). My mother knew many people in the small city where we lived. She had four siblings and many cousins, aunts, and uncles who shared a common last name. My father had also grown up there and had a business in this same city. We lived near the city center, where everyone went out on foot to complete their customary round of daily activities. These routines included scheduled visits to families in their homes and incidental, brief exchanges on the street or in stores. I became privy to the numerous encounters that my mother would have with relatives, friends, and acquaintances when she took me around. At her side, I absorbed the rhythm of the conversations, the movement of the speakers as they moved in close to share particular intimacies or opened up the circle of conversation to be joined by others or to acknowledge a familiar passerby. I absorbed the different forms of greetings that were used, depending on familiarity, and the variances in small talk that established common ground. I cannot count how many times I would hear a conversation that started something like, "You look very familiar. Do I know you from...?" and inserted was the name of a neighborhood, a school, or a community location. These interactions were the fabric and social engagement of my childhood.

My fascination with the conduct of interaction gets me into trouble with my friends and family, who sometimes bargain with me before going out to eat or to shop. They often say something like, "Are we just going to go there directly, or are you going to stop and talk to everyone on the way?" I guess they are trying to decide if they should wear comfortable shoes for standing around or, in the case of my son when he was younger, bring something to play with in anticipation of the inevitable pauses in the action. Often they extract a pledge when we enter a store that goes something like, "Promise me you will not be too friendly once we get inside." They may add a "tag" that includes a particular reason like, "We don't want to be there all day." Or they may just worry aloud, saying, "If you are too friendly, they'll know we're not from around here."

I supremely appreciate observations of person-toperson interaction and have a profound interest in how people relate with each other throughout their daily activities. It is an easy jump from this interest to a more focused look at the interactions that occur within a helping profession like occupational therapy, where we address how people navigate the occupations of their life and look for openings into those lives. 


\section{Resources in the Literature}

This lecture series honors [Eleanor Clarke] Slagle and her desire for others to reflect on and learn from therapy experiences. During my journey to "base camp Slagle," I filled the time between great ideas and landscapes with reading. I'd like to give you a quick glimpse of the literature I used to focus my attention on the study of interaction.

I started by getting to know the depth of literature within occupational therapy related to therapeutic use of self. I needed to understand how we use verbal and nonverbal behaviors to facilitate communication and found that although these specific skills received acknowledgment, they were not recognized for the depth of contribution they could make.

I read much of the literature generated by Adam Kendon (1990) and his associates in Conducting Interaction, including his work addressing what he called responses to Erving Goffman's early focus highlighting the need for in-depth study of "the countless patterns and natural sequences of behavior occurring whenever persons come into one another's immediate presence" (p. ix). Kendon (1990) and others describe the details of what occurs between people, including "where they look, when they speak or remain silent, how they move, how they manage their faces, orient to one another, and position themselves spatially" (p. 3). Examining these materials allowed me to develop an appreciation for the contribution that nonverbal behaviors make to the overall communication and interaction event. I came to understand and appreciate the experience when two people spot one another across a room and then, while walking toward each other, look away and prepare so that by the time they are close they can remake eye contact and greet one another. These behaviors are important when I consider how the therapy event is organized, how we prepare and conduct our own behavior with our patients and our colleagues in the work setting, ... manage miscommunication and awkward moments, and repair our own missteps.

During the many hours between the switchbacks and mountain roads moving toward base camp, I considered the use of gesture-and, in particular, Neapolitan priest Andrea deJorio's work Gesture in Naples and Gesture in Classical Antiquity (2000) — and came to recognize the use of one's face and facial expressions as well as one's hands in conveying an additional dimension to the communication process and how that may play out in interactions between therapists, patients, families, and staff. In addition, the conceptual and research literature addressing sequence organization in interaction, pragmatics in human communication, and quantification of kinetic behavior were helpful in constructing my understanding of movement and its role in interaction during a therapy session.

The body of work I explored also included patterns of organization in public behavior that led me to ask questions about my day-to-day movement in all of the different spaces I inhabit as I go about work and play in and around Philadelphia. How do I escape bumping into others as I negotiate the public transportation maze, crossing paths with throngs of people, jockeying for seats on the train, or finding where to stand on the subway platform? I became keenly aware of the idea of collision avoidance as well as the miraculous phenomena of interpersonal coordination and monitoring that allow us to remain in a continuous state of movement while reading one another's anticipated actions. This information is enormously useful in the negotiations of therapy spaces in the rehabilitation setting, clinic corridors, and the evercrowded hospital cafeteria.

I studied the classic, foundational work in verbal and nonverbal communication, including Edward T. Hall (1959, 1969, 1976) and Erving Goffman (1963, 1967, 1971). This influenced my understanding of the complex relations and "sequential temporal patterns of speech and gaze in dialogue" (Kendon, 1981) that we therapists manage each time we meet a new patient, attend a staff meeting, and participate in a case conference.

We use visual information and often do not think much about it, but I spent time developing an introductory understanding of the elegance of graphic display that Edward Tufte $(1990,2001)$ explained as he defined ways to visually represent and explain data. This provided some ideas for considering nontraditional data displays.

And, of course, I read the deep body of work in verbal and nonverbal communication in the medical visit and other patient clinician encounters, including work on patient satisfaction and the impact on outcomes, and gained momentum in my conviction that we must attend to verbal and nonverbal behaviors if we are to create data that prove the efficacy of occupational therapy.

In looking for explanations of visual and nonverbal storytelling, I struck gold in the literature of film and the consideration of the process of directing, including mise-en-scene or, as I learned, the things put in the frame to tell the story. In addition, I found that screenwriters use a prescribed plot paradigm to build visual stories with words and that an actor's ability to reenact and replicate emotion and action on demand defines that profession (Bordwell \& Thompson, 2010; Monaco, 2009; Osgood \& 
Hinshaw, 2009). I realized that therapists use similar methods when they "direct," "write," and participate in the therapeutic process.

\section{Therapy as Interaction}

The physical, emotional, and social context of any interaction is framed by its purpose. The interaction of a therapy session is unique. It is not the same as the interaction that we have in our casual exchanges with others. Occupational therapists conduct the business of therapy within a distinct frame of improving performance. Occupational therapists use physical space, therapeutic objects, their bodies, their voices, and their reasoning skills to create an interaction that produces therapeutic outcomes.

\section{Creating Meaningful Encounters}

Our lives as therapists are filled with certain kinds of encounters. For our patients and their families, the evaluation, consultation, and every particular therapy session has the potential to hold lasting meaning that is profoundly important. In therapy, we set the stage and begin the next chapter of the patients' story, giving them the skills to write what comes next and propelling them forward toward whom they will be. That ability to create those stories is the foundation upon which our profession is built. This is the way that we as professionals make a lasting impact on an individual's health and well-being. Finding the way to that success requires defining the story of the therapy encounter. For lasting meaning to occur and change in the course of a life, a therapist must be committed to behaviors that create interactional relationships.

With this said, occupational therapy is interpersonal interaction. Although the space that each of us creates as an occupational therapist reflects unique experiences and training, our profession's unifying commitment to the interactional relationship drives all of us to focus on the same priorities: providing our patients and their families with glimpses of what is possible, what can be done, and what it will take to get there.

You all bring clinical stories with you today. This convention hall is filled with those stories. They are exceptional and are the experiences that belong to all of us as occupational therapists. Those stories define our profession and speak to our commonality. This is why no matter where you are, what you are doing, or what your background might be, if you meet other occupational therapists, you immediately know who they are and what they do. You know what their life is like. We relate to one another immediately. This is the culture of our profession, and that shared culture creates the common experience of being an occupational therapist.

To define the interactional story, I plan to deconstruct a group of therapeutic encounters based on interactional time and events to answer questions that include, What happens in therapy sessions? What is the shared experience of being an occupational therapist? What defines our commonality? What do we typically do or say? And how do we set the space and move ourselves in and out of the action?

From the beginning of this project, I speculated that there is a particular set of verbal and nonverbal behaviors that must be in place to create a successful therapeutic encounter. I figured that if I could hear and see therapeutic stories being created, I would find common threads. These threads would lead me to a wealth of information about the verbal and nonverbal strategies that therapists use every day. To this end, I analyzed the data from a study with occupational therapists and their patients. Although the study was completed in a pediatric setting, I believe that you will see that many of the interaction findings apply to a wide variety of occupational therapy settings and patient populations. I have myself experienced their application to a broad range of patient encounters, including when I observe occupational therapists in adult acute care and rehabilitation, hear stories about working with adults who have developmental delays, review cases from our Alzheimer's disease projects, or watch students in patient simulations with individuals who have psychosocial difficulties.

\section{The Study}

In the study I am discussing this evening, qualitative data were collected from four occupational therapists who worked in an early intervention, community-based setting. Each of them was observed and recorded in at least two clinical encounters. They performed evaluations using the Peabody Developmental Motor Scales (Folio \& Fewell, 2000) and collected additional physical and historical information about other aspects of the child's performance contributing to the overall evaluation. Some of the observations were initial evaluations in which the therapists, young children, and families were new to one another and occupational therapy or new to one another but familiar with occupational therapy. Some of the sessions were reevaluations with therapists, children, and families sharing the camaraderie of interacting with one another over a period of time, creating change and celebrating improvements that reflected the investment of time and effort, worry, and concern. Evaluations were conducted in homes and in the early intervention agency. Some sessions were with just the therapist, child, and 
parent or grandparent. Others included members from the team or multiple family members.

\section{Interactional Model}

I recognized some basic interactive and contextual information about the therapists in the study that could be organized and analyzed by developing a simple model (Figure 1).

\section{Entry Education in Occupational Therapy}

The first commonality is professional education. The four therapists who participated in this project had completed their entry-level education in occupational therapy from four different educational programs via two different entry routes (bachelor's and master's).

\section{Individual Profile}

Following their graduation, the therapists developed their own unique individual profile. Like a fingerprint, a therapist's profile is distinctive. It represents a composite of experiences that are formed as each therapists works, reads, is mentored, observes other therapists, and matures into a professional.

\section{Specialty and Advanced Training}

The therapists accumulated specialty and advanced training based on their individual interests. They attended different conferences and workshops, continuing education programs, and in-depth specialty training and studied for advanced degrees (two specialized in early childhood).

\section{Professional Belief Systems}

Their unique profiles revealed individual professional belief systems. These belief systems guide, focus, and determine what a therapist will do in a given situation and are demonstrated when occupational therapists focus on different concerns during an evaluation or treatment. Professional belief systems are evident in the selection or exclusion of topics addressed during the course of the session and the amount of time devoted to each particular topic.

For example, some therapists were more concerned with a line of inquiry about movement; others focused more attention on development, play, family time, daily routines, or mealtime. Similarly, some therapists excluded some topics (disease management, sleeping or digestive issues, dietary problems), as they did not see them falling into their domain of concern.

\section{Theoretical Perspectives and Expertise}

Finally, individual profiles included preferred theoretical perspectives and expertise. These are based on an individual's education, training, and preferences as well as their professional expertise developed in different work settings.

These four therapists (depicted in this model as T1, T2, T3, and T4) brought their professional education and individual profiles to the therapeutic interactive encounters studied.

\section{Therapeutic Interactive Encounter}

Once engaged in the encounter, the therapists directed complex action and interaction as they (1) used verbal behaviors, (2) used nonverbal behaviors, and (3) interacted with co-participants within the given settings and contexts of the evaluation.

\section{Identifying Points of Analysis}

Given this interactional model, the next issue to confront was to identify appropriate places to launch an analysis within the real-time therapeutic interactive encounters. Because the events unfold in a more or less orderly fashion, it is possible to find like points for comparisons. As I watched these encounters, I identified points of analysis or

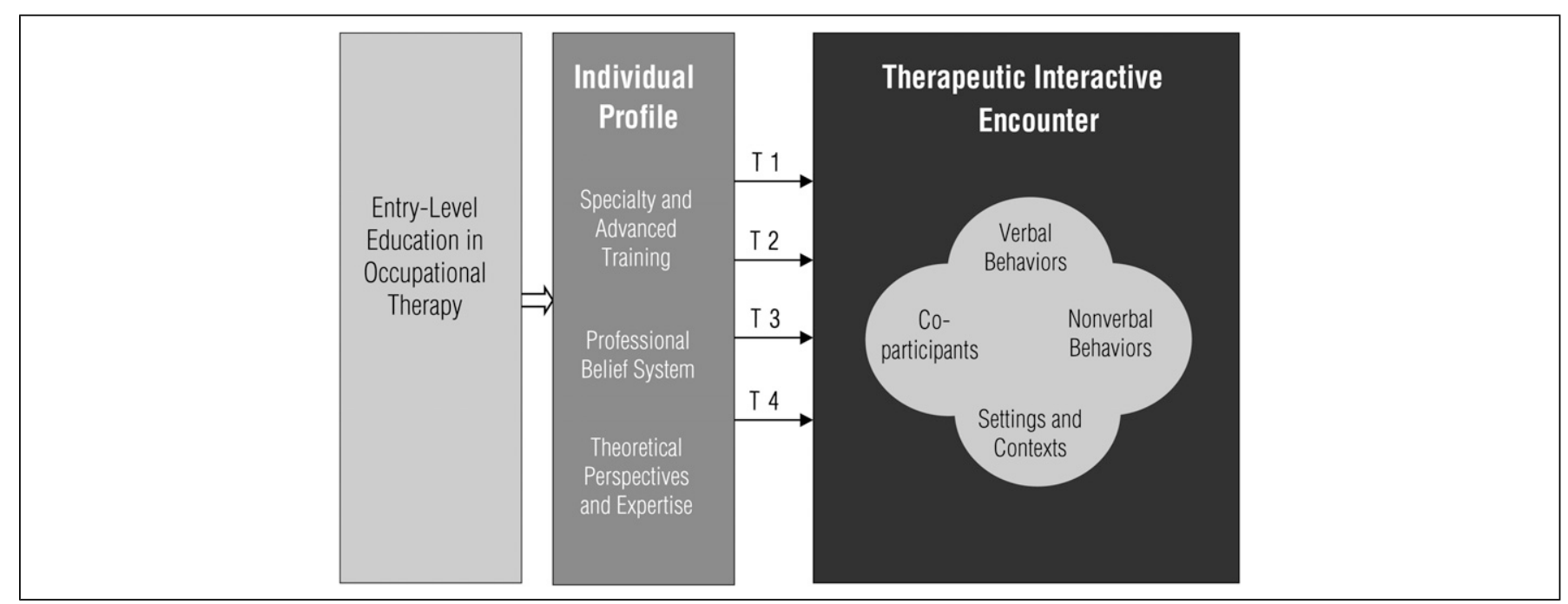

Figure 1. Interactional model. 
a point in time where there was a shift in the action. This point could be identified as a therapeutic juncture.

Examples of therapeutic junctures include a point when the therapist does something that demands action. The therapist can ask a question, move to the next task, provide a new movement challenge, and so on. The juncture provides a point at which the interaction between the therapist and patient or family member can be observed, analyzed, and deconstructed. These junctures cause shifts in action that allow the encounter to exponentially expand as the encounter progresses. What better place to deconstruct an encounter than at these single junctures?

Argentine writer Jorge Luis Borges (1962), winner of the first international publisher's award, wrote a short story about this moment titled The Garden of Forking Paths. In the story, the antagonist discovers that the particular path taken after entering an ancient garden of forking paths defines the future. These paths sometimes reconverge and cross over a vast labyrinth in time and space. That labyrinth leads to many possible ends in differing times at different places. The short story, written over 60 years ago, is considered the birth of modern hypertext stories and remains current today as the foundation of many popular television programs, from Lost to Flash Forward.

It is interesting to think of "differing paths" as they apply to the therapeutic encounter. In this project, I chose a set of single junctures where a path begins and where I could observe, analyze, and deconstruct verbal and nonverbal behaviors. By taking these single junctures, I could discover how therapists create therapeutic interaction, manage information, and direct action during therapy sessions. This knowledge provided insight into the scope of behaviors used and decisions made throughout therapeutic encounters.

\section{What I Learned}

The data obtained exemplified the variety and complexity of roles that therapists must take as they produce and direct a successful encounter. In all, the occupational therapists were clearly highly skilled professionals who knew what they needed to do and how to make it happen. I came to see therapists in a role very much akin to that of the director of a film. Like film directors, therapists "work closely with the cast and production crew and involve others in the process of storytelling while taking responsibility and making important decisions" (Osgood \& Hinshaw, 2009, p. 6). Film directors fully conceive the project well in advance of the first day of production. Therapists need to conceive and know the possibilities that a therapeutic interaction can produce and, like directors, need to "possess experience in the production process and have a strong sense of story development" (Osgood \& Hinshaw, 2009, p. 6).

\section{Reciprocal, Reflexive, and Complementary}

The complex nexus of therapeutic interaction occurs in real time during face-to-face encounters. It engages coparticipants in reciprocal, reflexive, and complementary interactions. Therapeutic interaction is reciprocal and reflexive in that it occurs based on relationships of alternating, sequencing experiences across successive moments of real time. I say or do something, and in turn you respond by saying or doing something. Every action begins with a motivation and creates a reaction.

Verbal and nonverbal partners also react in retrospective actions. They take into account what the other is doing or has done and prospectively anticipate what will happen next.

Finally, interaction is complementary. It depends on relationships between simultaneous actions of interactional partners. It unfolds in a natural order like any turntaking event that requires you to take account of another and make a reasonable response. Sometimes responses can be unreasonable. Sometimes they can be fraught with missed signals and divergent streams of talk.

\section{Social and Cultural Conventions}

There are social and cultural constructs or conventions that contribute to the organization and construction of the interaction, and they vary based on the persons who are present. Likewise, therapeutic interactions are also socially and culturally constructed. You know this from your own experiences. Patients who are recent immigrants, older or younger, male or female, working class or professional, will respond quite differently to the experience of being seen in a hospital, clinic, rehabilitation center, private office, or their own home. Each brings with himself or herself his or her own understanding of what is to be done and how one must conduct oneself. The interaction occurs as a partnership between therapist and the intended coparticipant. That it occurs simultaneously and with a synchrony is testimony to each participant's ability to read and respond to one another and the therapist's ability to direct this complex set of action and words.

\section{Fine-Grained Detail of Occupational Therapy}

The fine-grained detail of occupational therapy is revealed using a technique called microanalysis. Looking 
at videotaped material at normal speed will be a realtime analysis. I wanted to slow down real time to understand the very subtle things that happen between therapists and patients in the therapeutic space at those key junctures.

Microanalysis is a technique that allows each action or movement or sound to be slowed down. Using microanalysis, each interaction is viewed in $1 / 30$-second increments. It is a frame-by-frame analysis of action and sound. To understand this level of specificity, recognize that each 1-hour therapy session yields 108,000 frames. Each of these frames can be individually analyzed. Although I looked at all 108,000 frames for each session, I only chose a set of frames to analyze. Of those selected, I mapped each action and sound change frame by frame so that single actions could be microanalyzed. These sets of frames represent similarities and differences across the recorded therapeutic junctures. I'll turn now to the analysis.

\section{Analysis of Verbal Behaviors}

Therapist use both direct and indirect verbal requests throughout a session. In the data set, both types of requests were used to elicit information. In addition, it appears that verbal remarks are used to draw a participant's attention to specific actions. Therapists might want to indicate that they are noting a change and improvement in the child, and so they say, "I see we like to color, don't we?" They may wish the parent to say or do something to encourage the child, indicating that desire by saying, "Make a picture for Mommy" or "String a necklace for Mommy." They also use what I call "out-loud" talk to signal the importance of what they are observing: "I see you are using both hands" or "You've got very nice sitting balance." This type of interaction is a way of drawing attention to the purpose of occupational therapy.

\section{Participants in a State of Readiness}

Therapists expect the parents, or who I am calling the participants, to give their complete attention to the action at hand, to be "in the moment," and to be ready to provide information as requested. As a result, participants are in a state of attentive readiness. They must be alert, recognize requests, and supply the requisite information or action.

Participants hold up their end. They return the therapist's eye gaze, turn to face them, answer questions, and show interest and willingness to share talk and action for a common purpose. They engage in a joint construction of the interaction. As you will see, this latter behavior requires some experience on the part of the participant.

\section{Direct and Indirect Requests}

Direct requests and responses can be mapped out in a diagrammatic structure (Figure 2). The point of comparison is between new or novice participants (those for whom this is the first occupational therapy experience) and experienced participants (those who have been actively engaged with their child in occupational therapy for at least 6 months). The experience of therapy for each of these two groups of participants was clearly different.

The novice participants are fresh to the therapy interaction. They are essentially "feeling their way," figuring out the terrain in this new land. They are in the beginning stages of forming an understanding of what an occupational therapist does during an occupational therapy session, the primary areas of focus, the materials used, and the types of questions asked.

When asked direct questions, novice participants tend to give short answers (1-5 words) that have little to no detail, or they may simply head nod or shake their head in response.

An interaction is initiated by the therapist in the form of making a direct verbal request. If the direct request does not have a cue (e.g., eye gaze, use of the participant's name), then it is not recognized as a request by novice participants. As a result, they do not respond.

In the second iteration, the therapist makes a verbal request to a novice participant, but this time he or she tags it with a cue, an eye gaze directed at the novice participant, or the use of the participant's name. In this instance, the new participant recognizes the request and will respond, albeit briefly.

The novice participants are compared with those who have been receiving occupational therapy or have previously received occupational therapy or a similar intervention (e.g., physical therapy, speech therapy). I refer to these individuals as experienced participants. Because of their ongoing interaction with the occupational therapist, they understand the kind of information that is needed, and they can apply what they have learned from previous sessions.

Experienced participants respond regardless of whether there is a cue to them. They are able to recognize the request based on their past experiences. They know therapists are constantly collecting information, and they are willing to participate in this endeavor by providing detailed or additional information. Let's look at some examples of this type of interaction.

\section{Direct Requests for Information}

These first samples provide an illustration of the backand-forth verbal interaction between a therapist and a novice participant (Figure 3). These exchanges are 


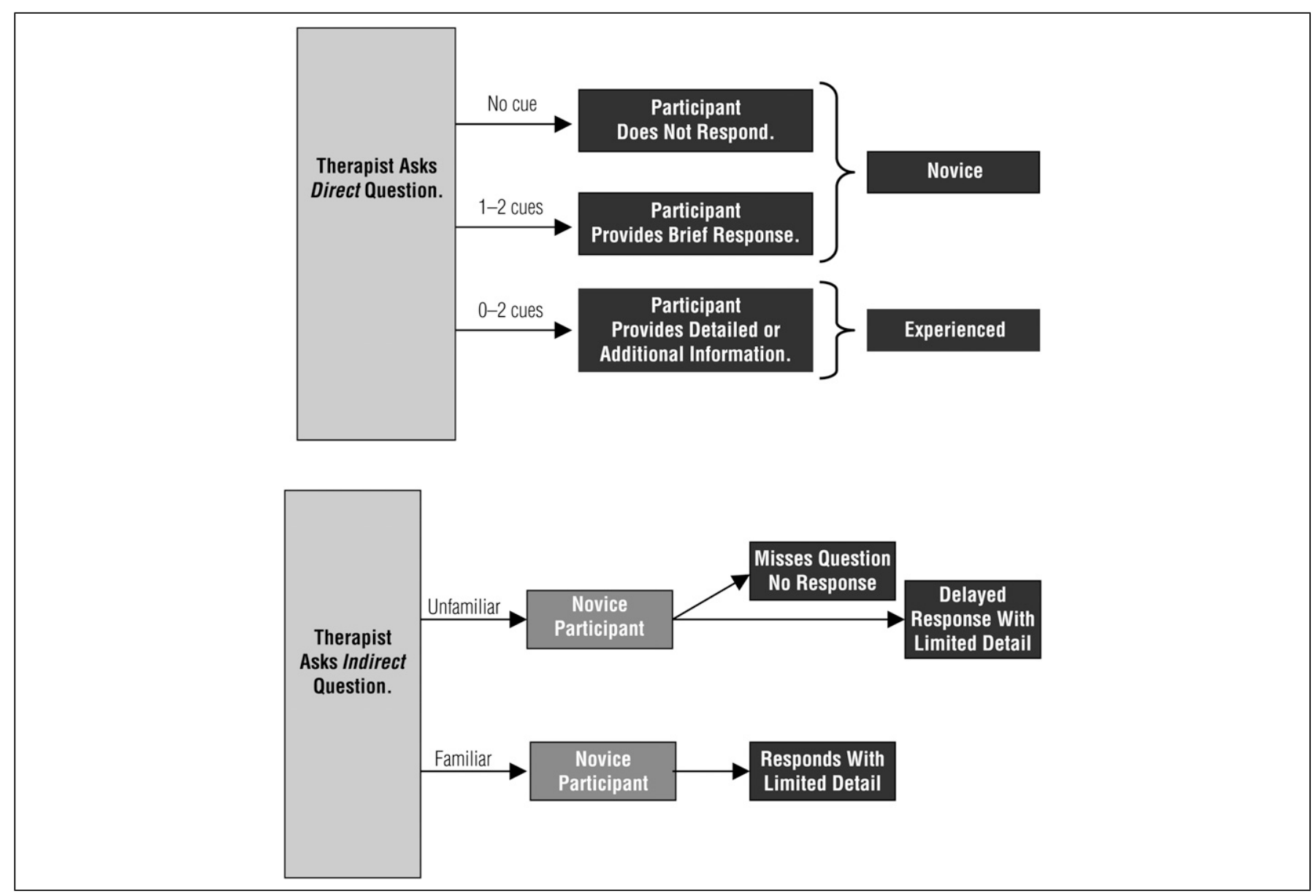

Figure 2. Responses to therapist's direct and indirect questions and cues.

characteristically short in response length and detail (they may consist only of a gesture) because the participant is a novice.

\section{Child With Ring Stack}

T: Does he have this at home? Does he play with it? M: No, he doesn't.

$\mathrm{T}$ : Have you ever seen him put a ring on? M: No.

\section{Child Poking Finger}

$\mathrm{T}$ : Will he poke his finger in? (Therapist gestures poking.) M: (Mother nods yes.)

T: He seems to be using a pincer. (Therapist holds hand up and demonstrates.)

M: Yes.

$\mathrm{T}$ : Does he look at a book?

M: Yeah.

$\mathrm{T}$ : Does he look at pictures?

M: Yeah.

Therapists may be able to solicit longer responses with some detail from novice participants when they are close by and using intense eye gaze and even emphasized postural orientation. In this next case example, the answers are longer when the therapist says "okay" or asks for specifics, indicating she wants more detail. In this way, the novice participant is encouraged to elaborate when provided with prompts.

\section{Child Playing With an Object at a Small Table}

$\mathrm{T}$ : In terms of feeding, what does he do?

M: Real good by himself. He's feeding by himself.

T: Using?

M: He tries to use the spoon.

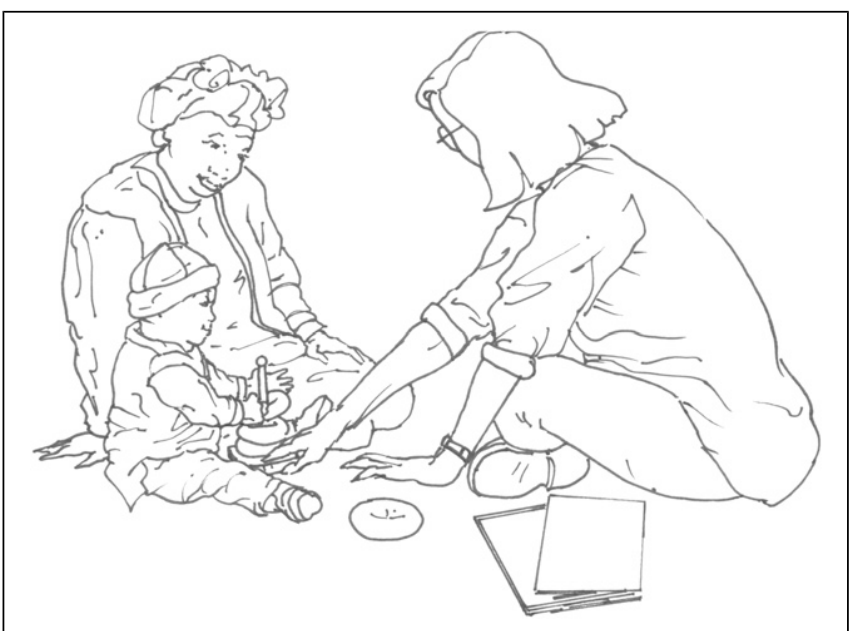

Figure 3. Line drawing of therapist, child, and mother. 
T: Okay.

M: (no response)

T: Okay.

$\mathrm{M}$ : (no response)

$\mathrm{T}$ : Drinking?

M: He would rather drink from a cup.

$\mathrm{T}$ : His choice is the cup?

M: Yeah, his choice is the cup.

In this sequence, we heard the continuous turn taking that is emblematic of interaction. The sequence is a beginning: It provides a first step toward interaction that is reciprocal, reflexive, and complementary with the simultaneous action of the interactional partners. The parent sustained a longer chain of information as the therapist supported each response and provided prompts to encourage even more answers.

\section{A Word About Line Drawings}

As a point of reference, line drawings were sketched directly from the images grabbed off of the videotape recordings. The drawings are used in the same manner and for the same reason that Kendon (2004) described in his work Gesture: Visible Action as Utterance. He suggested that "drawings are generally preferable to camera-ready picture frames pulled directly from the videotape. Not only can one show, in the drawing, just the details that are pertinent for the exposition, but the problem of showing photographs of people who might wish to remain anonymous is completely avoided" (Kendon, 2004, p. vii). In this way, line drawings allow me to focus your attention on the action that I was attending to in the analysis without distracting you with the extraneous details that were present in the backdrop of the real-life setting. In addition, the line drawings avoid the temptation of critiquing the setting, the materials, the dress, or other similar off-the-point (irrelevant, unconnected, or secondary) details of the action.

\section{Direct Requests With Experienced Participants}

The direct-request situation is substantially different when the participant is experienced-someone who has "been here before." Experienced participants are acquainted with the rhythm and the timing of the session, they are aware of the information that is of primary concern to the occupational therapist, they recognize the openings and opportunities for providing that information, and they understand the kinds of responses that are expected of them and how they contribute to the session and to the therapeutic enterprise.

Direct requests with experienced participants are answered with more precise, detailed information. For example, the therapist asks, "What kind of stroller is he in?" The mother answers, "It has back support." The mother has shaped the information with specific detail based on what she understands the therapist cares about and needs to know. Let's look at some more examples.

On the first visit to the community-based agency, a little boy is accompanied by his mother and his cousin, who is visiting for the summer. Within the first minutes of the session it becomes apparent that the mother is an experienced participant. She knows her way around therapy - what occupational therapists are interested inand she gives information within that framework. In response to the therapist's questions, she explains her son's behavior with thick, richly detailed descriptions. In contrast to the novice examples, her experience is evident by the length and detail as well as her use of key words.

This mother demonstrates that she knows what occupational therapy is about and what therapists focus on, as evidenced by the kinds of things she chooses to talk about (e.g., he likes being in the water and the connection to aquatherapy), the language used to describe her son's behavior (e.g., reaching and using his trunk), and other details (e.g., "I see him trying a lot harder"). Similarly, she shows her understanding of the relationship between therapy and function, commenting that she saw him sitting up by himself more after therapy. In other portions of the interview, she gives thick, detailed descriptions of how her son eats, his use of his hand, and his resistance to others feeding him. With her knowledge of occupational therapy, she is able to observe her own child in other settings and at home and bring those details of her child's strengths and needs to the therapist.

\section{Indirect Responses}

Indirect questions are more subtle in nature and more difficult to identify as a question to be answered. When an indirect question is asked about an unfamiliar topic, the novice participant may miss the question and make no response or give a delayed response with limited detail. When the topic is about something that is familiar to the participant, the novice participant responds with limited detail.

The next example represents the kinds of responses that occur with a novice participant. This is the first home visit for this family. The child being seen is one of a set of twins. The little girls are 6 months old and were born prematurely. The first 6 months of parenthood with these twins was spent addressing a host of issues secondary to their prematurity.

At the start of the visit, the mother recounts the history with doctors to date. From her stories, it is clear that she is 
used to being in the role of listener. She shares her experiences with experts who, in her words, "don't say much." Based on this mother's comments and her experiences in settings such as the neonatal intensive care unit, we can safely speculate that her role has primarily consisted of being a silent observer: watching the expert.

In contrast, this occupational therapy session in her home is a dramatic change and, in all likelihood, is the first time she will be asked to participate in a collaborative way. The start of this session is rocky as she gets her "sea legs" and begins to understand what occupational therapy is all about.

The mother is seated on the sofa, holding one of her twin babies. The therapist has positioned herself on the floor with the other twin, directly in front of the mother. The therapist observes the baby while making notes. She continues to look at the baby while asking what I have categorized as an indirect question, and it is to the baby. It goes like this:

T: "You don't mind being on your back. Are you looking at the light?"

The mother makes no response. The therapist knows the baby won't answer, but she expects that the mother will. This is not the case, because this mother is new to occupational therapy and does not quite understand how it works. The therapist, an ever-vigilant director of the interaction, recognizes that things have not gone as expected and makes the necessary corrections and modifications.

Ten seconds later, the therapist asks her next question and provides an added cue-her eye gaze to the mother. She says, "Does she always lay to one side?" In this instance, the mother sees the eye contact, recognizes the question is for her, and responds, "Yeah."

For the most part, novice participants miss requests that are indirect and unfamiliar to them. This is evident in this case. In some instances, novice participants are able to catch a therapist's request, even if it is indirect. They understand the request because it is familiar-something any mother, father, or grandparent is routinely asked, because they are a mother, father, or grandparent.

In this next example, mother and therapist are in the same position. The therapist is visually involved with the child without any eye contact or other cues for the mother, such as use of her name. But in this interaction, the talk is familiar. The therapist says, "Who is older? You or your sister?" The mother answers for her child, "I am." The response is noted in the change of her eye gaze to the therapist. She responds to this indirect request because it is about a familiar topic and one she has heard and will hear time and time again as the mother of twins.

\section{How Do Novice Participants \\ Gain Experience?}

Therapists teach participants about the verbal and nonverbal behaviors that are common in the world of occupational therapy. They do this by working with the participant and establishing a mutual focus on the specific skills and concerns that warrant their attention. They shape questions as direct requests, such as "I wanted to ask you...." and place themselves at eye level, looking right at the participant. They also talk out loud in an effort to make the participant aware of what they are doing, what they are observing, the reasons why they are doing it, and the expectations they have for the future. Therapists say things like, "I'm looking at what he does with one hand and with two" or "He's starting to transfer. He's letting go." Within a short period of time, novice participants learn from their therapists and gain experience. In this way, a novice participant becomes an experienced one.

\section{Experienced Participants Respond to Therapists' Indirect Questions}

In contrast to novices, experienced participants recognize opportunities to provide information regardless of whether the question is familiar or unfamiliar. They see this as a way to give details about what is going on beyond the four walls of therapy.

This next example takes place during a reevaluation in a community-based setting with the grandmother, therapist, and child. The action occurs within the first moments of the evaluation session. The therapist is waiting for me to indicate that the recording crew is ready to begin. While they wait, the therapist and child play around. The grandmother watches and recognizes an opportunity for the child to show what she is beginning to do at home.

With impeccable timing, this grandmother, an experienced participant, recognizes what is needed and not only provides information during the play time, such as, "Say your alphabet; she's starting to say her alphabet," but also modifies it once the therapist begins rattling off the alphabet too quickly, adding, "No, slower, just one at a time." The grandmother knows that this is the kind of information this therapist focuses on and could be of use to this therapist right now. These verbalizations contribute to the interaction's success.

Experienced participants take active roles in the session. They bring up their own familiarity and understanding of the behaviors that are the focus of the occupational therapy and they initiate related topics. 


\section{Ignoring Topics}

Therapists may (1) ignore topics or (2) interrupt participants over the course of an interactive encounter. These two behaviors are a direct consequence of the therapist's responsibility for keeping the focus of the interaction on topic and accomplishing what he or she set out to do within a given time period. These behaviors also seem to reflect therapists' willingness to address only topics within their defined theoretical perspectives and expertise. This type of response to off-topic material is extensively written about in the medical encounter literature. For example, when therapists define behavior problems as residing outside of their professional belief system and expertise, then in all likelihood, topics related to behavior will be ignored. This may not be an example of "best practice," especially if we believe that our role is to understand the whole person, but it does occur.

Similarly, novice participants who are not yet familiar with what is included and excluded in occupational therapy may introduce off-subject topics. These topics may be ignored or given minimal attention by the occupational therapist. For example, when a therapist was asked to speculate about a young child with cerebral palsy and his potential to be a wheelchair athlete, the therapist acknowledged the comment and redirected to a new therapy-oriented topic.

Experienced participants are also inclined to make their own requests, remind therapists of topics that need to be addressed in the session, or bring up areas of concern that may be off topic. Therapists work to redirect the focus, even if it takes some time. Here is an example from a reevaluation. The therapist has just shifted the action from playing with a toy that facilitated the child's reach, grasp, and release. The child kept putting the toy in his mouth, and now the therapist is turning her attention to his oral-motor skills. The therapist's and mother's words overlap, and the therapist repeatedly attempts to redirect the topic.

T: How ya doing with eating? Oh, well then

M: He had a whole jar of baby food before we came here, um...

T: you should be full. Look at you. Yor goin need a bath.

M: But we're giving him juices-And instead of so much milk

T: Is that helping? With the congestion?

M: all the time, we're giving him more juices and —and water-

Umm, I

$T:$ You looking at

M: don't know if it's helping. I'm trying to see if it'll help his bowels to go more easily....
T: yourself? Who's that kid?

M: Because most of the time that Pediasure is not doing it, for me. I mean,

T: He's getting tired. Not as bad?

M: it's like... He's straight now, but not as bad as he used to. But the...

T: Let's try one more thing.

M: Pediasure milk, boy, I'm telling you, that stuff is expensive. I've got to walk three

T: One of things I want to do.

M: blocks away to get it.

The mother brings up a topic that is of concern to her (her child's eating and digestion) that she knows has been of interest to this child's team in response to the therapist who has asked about eating. The therapist is not concerned with the dietary and digestive aspects of the issue (she indicated in a follow-up interview that she believed the issue was best discussed with the team's nurse), so she works to move to a topic within her domain of concern.

\section{Forming and Reforming Interactional Space}

In the eight evaluation sessions, therapists all engaged in forming and reforming interactional space. Therapists seemed to be quite deliberate in placing themselves and the participants in ways that facilitated interaction and communication. They did this for two key reasons: (1) to elicit the child's best performance and (2) to provide signals of their intentions to others. Each therapist seemed to have "customary ways," or unique styles, to set up and use the four walls of the interactional space. They created these spatial arrangements to be sensitive to nonverbal information and have access to head movements, eye gaze, body movements, and gestures.

In an example of forming and reforming an interactional space, the therapist introduces a ring stack toy; moves away a small table; adjusts the child's feet, setting them apart; turns the ring stack upright; and holds it for him to facilitate his performance all within a dense complex of seconds.

To shed some light on this dense complexity of words and actions, I want to tell you about an analytic technique used for displaying the local geography of action. In searching for a way to visualize the complex and multiple foci of action in a video sample, I considered a number of options. One in particular was the idea of developing an adaptation of musical scoring, mapping the different movements and dialog of the participants like the orchestration for multiple instruments. This was very 
foreign to me because I only know how to read music at a very elementary skill level. At any rate, I later discovered a technique that I called conversation convention, short for conversation and movement convention, and my research team quickly adopted that language. When we sat down and began to deconstruct the dialog and action, it became apparent to me that we needed a more elaborate way to map the multiple parts presented by the therapist, parent participant, and child, each of whom contributed words and actions. We quickly changed over to the established vernacular of displaying local geography of action.

Based on Christian Heath's (1986) work Body Movement and Speech in Medical Interaction, we were able to decode the precise words and actions of all participants during an encounter and the location of the various elements and their interrelation at points in the data. Heath's "rough and ready" method proved useful in mapping focus on the action and provided "an analytic device for developing a sense and picture of its detail" (pp. 18-19). The convention used here is my own iteration of his technique. Figure 4 illustrates the total voice and action that occurs in 11 seconds. You see the name of the speaker and the dialogue in large, bolded print. You also see a notation for the time and a small $v$ or caret, which is the convention used to indicate the origin point for the action. Each line above the dialogue is labeled for the person contributing the action. Coincidentally, this type of notation is extremely similar to that used in the professional editing of video and sound.

In this illustration, we can get a real sense of the complexity of action that the therapist is directing. Specifically, the therapist is talking, and the child, mother, and therapist are all moving and participating in the action. When these segments are scrolled in real time, you can get a sense of the ongoing stream of interaction that occurs throughout an encounter.

Therapists seem to have exemplary interaction skills. They move themselves, others, and objects within short periods of time into positions that make sense for the task at hand. They use verbal comments to announce their intentions and underscore what they see.

In this next example, the therapist carefully plans the timing of the re-formation of the interactional space. She takes into account a number of variables and waits until the time is right for success. She re-forms the interactional space based on a number of key factors, namely (1) what she knows about children in this developmental stage and how to get them to do something you want them to do; (2) what she knows about this child in particular, since he has just developed a strong interest in using a marker; (3) what she knows from her repertoire of experience about the kinds of positions and surfaces she needs to accurately assess his skill level; and, finally, (4) what she believes will work in a situation like this.

The session begins with the child sitting on a chair at a table. He quickly tires of the confinement, and the therapist is able to set up a new center of action on the mat. Now they have come to the line-drawing challenge of the Peabody assessment (Folio \& Fewell, 2000), and the therapist finds herself stranded on a mat.

When she presents the line challenge, the child is sitting. The child responds by lying on his side and beginning to draw. Once the therapist has recognized the problem (the child will not be able to do his best in this position), she allows him to "give it a go" while she formulates an alternative plan of how she will get him into a seated position for drawing based on his own initiative (i.e., making the tabletop look enticing, moving those very desirable markers to the table, and having him move as his own idea rather than placing him in a seated position) and then executes it with a remarkable precision. The therapist proves to be quite effective in using herself, the setting, and the props.

Therapists are able to use interactional space, even when it is extremely limited and they are, in a sense, constrained by the environment. This example is from the evaluation session in a very small row home in Philadelphia. The mother is seated on the sofa between two people from the early intervention center. The therapist is on the floor, supporting the child in a standing position. A fourth member of the early intervention team is beside the therapist, as are two of the child's siblings. In this very small interactional space, the therapist was able to reform it and make postural shifts that allowed her to signal others that she was giving her full attention to the child. Later, when she completes the assessment, she sets the child up to play independently with a toy; puts her assessment materials away; picks up her papers; and makes postural shifts, turning herself toward the mother on the sofa and clearly signaling that she had completed her assessment with the child and was ready to ask the mother some questions and give her some important information.

\section{Experienced Participants Stand at the Ready}

Novice participants are more likely to observe the therapist and offer support for their child during an interaction. In contrast, experienced participants appear more comfortable being involved and responding. They "stand at the ready," poised to respond if needed, and 


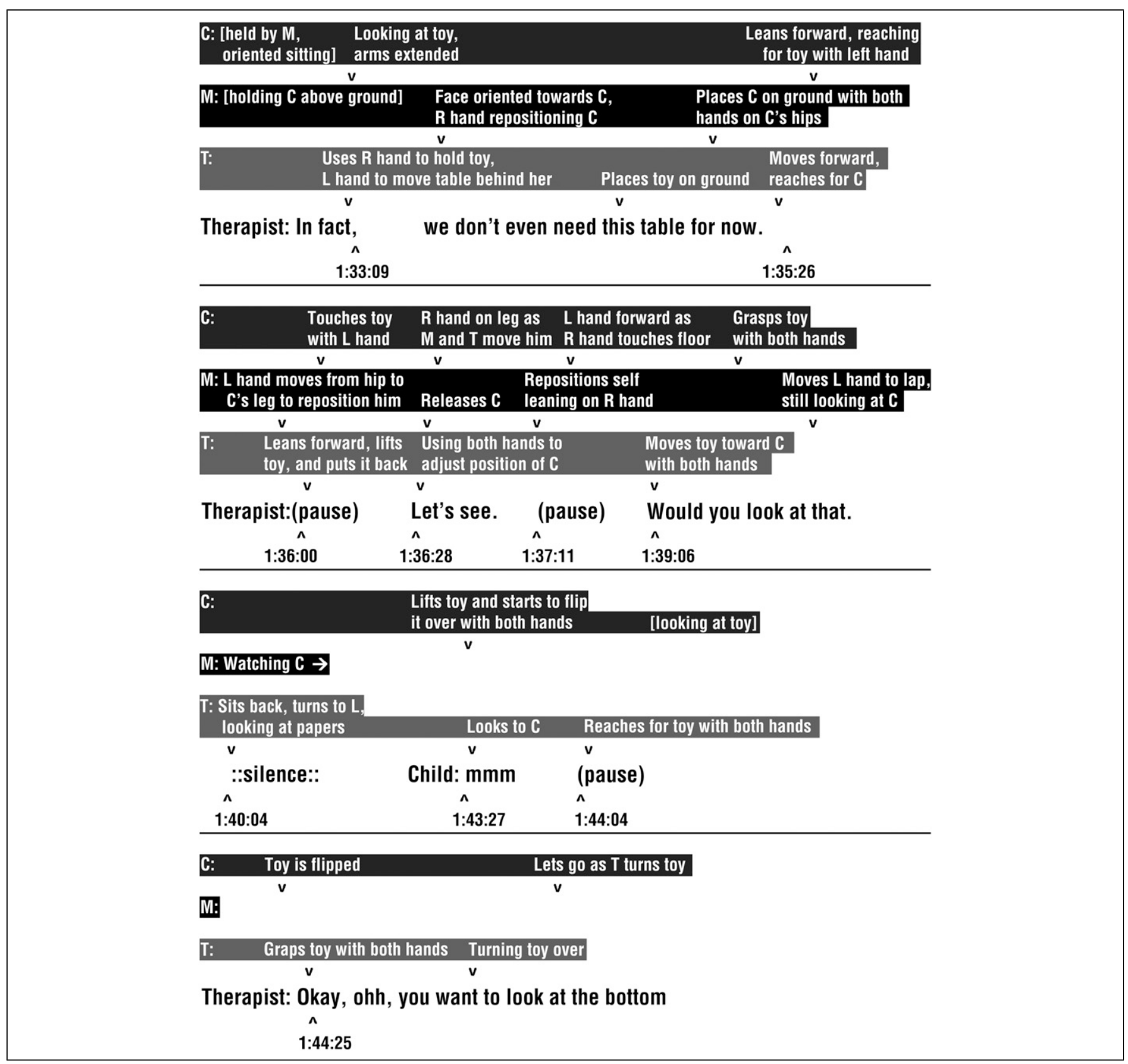

Figure 4. Total voice and action.

Note. $\mathrm{C}=$ child; $\mathrm{M}=$ mother; $\mathrm{T}=$ therapist; $\mathrm{R}=$ right; $\mathrm{L}=$ left; ${ }^{\wedge}$ or $\mathrm{v}=$ origin point for action.

become actively involved to support the successful performance of their child. They are the backup. Therapists often offer them a position close by or give them signals to move into the action when they are needed to roll up a child's sleeves, coax the child to do something, and to remove "troublesome" objects from the child's line of vision. They develop their own repertoire of positions so they can move in or out of the action quickly, unnoticed, without words or direction, and they provide "frontline" information about an emerging skill that they know the therapist is following.

Experienced participants are able to insert themselves into the frame of action and extract themselves as needed.
This is strikingly evident when we look at the synchrony of words and actions that occur in a very short period of time across a session with a young child, experienced participant, his mother, and a cousin.

Remarkable action occurs in a segment that lasts 22 seconds. The therapist has finished asking all of her initial questions, and she is beginning to move into the "handson," child-oriented portion of the assessment. She has shifted her postural orientation from the mother to the child and re-formed her interactional space and her eye gaze to the child, clearly sending the signal that this is where her focus of attention is for the time being. The mother, an experienced participant, is seated to the left 
toward the back of the child. A cousin is in the foreground. The therapist reaches to her left to bring in a colorful toy, which is a set of plastic links fastened together as a chain to capture the child's attention. She places it in front of the child.

The mother, an experienced participant, recognizes what is going on: The therapist wants to attend to and assess the child's sitting balance, and so she verbally moves into the action to shift her child's attention away from the what the therapist is doing (challenging his balancesomething she knows her child does not like), saying, "Wow, look at all of those beautiful colors." Her son hears her and responds to her words by looking in her direction.

Then, without any prompt, she reaches into the play space to draw her son's attention to the toy, unlinks it, sets it down in front of him, and ends up handing it to him. Once the child has the toy, he brings it to his mouth while his cousin catches hold of the other end in a playful gesture. The therapist is able to continue her physical assessment of the child without protest from him.

Sometimes the parent is a catalyst for the therapist to shift her own focus, letting the mother have a hand at the action. With experience, participants are able to place themselves in the action and fully participate without verbal or physical prompts or even eye contact with the therapist.

\section{Conclusion}

In this talk, I have shared my passion for interaction and showed how it directly connects to the very core of our profession. I have established a model of interaction and defined the components that shape the therapeutic actions and space created by occupational therapists.

In doing so I have summarized what I have learned as I journeyed to the base camp that Eleanor Clarke Slagle founded so long ago. I guess that if this was one of my Slagle dreams, we'd all be dressed in climbing gear, ready to scale and conquer the mountain that still looms before us.

Tonight, I know that the journey I took beyond base camp defines a new route to the mountain peak and points a way for others to see interaction as the cornerstone of our profession. Interaction can be a powerful way to understand the efficacy of occupational therapy and share the reasons why our therapeutic approach works so well. This new understanding can change the conversation about the exceptional contributions our profession makes to health and wellness.

I hope this fresh viewpoint will situate others to look deeply at the basic interaction that defines our profession.
This pioneering direction can stimulate innovative areas of research—areas that build on the strength of our founders' foresight and redefine a shared vision for our future.

\section{Acknowledgments}

My thanks go out to my colleagues and friends at Jefferson, AOTA, and beyond who believe in me and gave me wonderful support along the way; my assistant Kerri O'Rourke, who is fast, smart, and just plain fun; my sweet son and my amazing daughter-in-law, who always made time and space to ask about my progress on the Slagle; and my husband, Neil, who knows when to step in and out of the frame, isn't afraid of heavy lifting, and has a remarkable gift for argumentation and organizational detail.

\section{References}

Bordwell, D., \& Thompson, K. (2010). Film art (9th ed.). New York: McGraw Hill.

Borges, J. (1962). The garden of forking paths. In J. Borges, Ficcones (pp. 89-101). New York: Grove Press.

deJorio, A. (2000). Gesture in Naples and gesture in classical antiquity. Bloomington: Indiana University Press.

Folio, M. K., \& Fewell, R. R. (2000). Peabody Developmental Motor Scales (2nd ed.). Austin, TX: Pro-Ed.

Goffman, E. (1963). Behavior in public places: Notes on the social organization of gatherings. New York: Free Press.

Goffman, E. (1967). Interaction ritual: Essays on face-to-face behavior. Garden City, NY: Anchor Books.

Goffman, E. (1971). Relations in public: Microstudies of the public order. New York: Harper \& Row.

Hall, E. T. (1959). The silent language. New York: Anchor Books/Doubleday.

Hall, E. T. (1969). The hidden dimension. Garden City, NY: Anchor Books.

Hall, E. T. (1976). Beyond culture. Garden City, NY: Anchor Press/Doubleday.

Heath, C. (1986). Body movement and speech in medical interaction. Cambridge, UK: Cambridge University Press.

Kendon, A. (Ed.). (1981). Nonverbal communication, interaction, and gesture. New York: Mouton.

Kendon, A. (1990). Conducting interaction: Patterns of behavior in focused encounters. Cambridge, UK: Cambridge University Press.

Kendon, A. (2004). Gesture: Visible action as utterance. Cambridge, UK: Cambridge University Press.

Monaco, J. (2009). How to read a film: Movies, media, and beyond (4th ed.). New York: Oxford University Press.

Osgood, R. J., \& Hinshaw, J. (2009). Visual storytelling, videography, and postproduction in the digital age. Boston: Wadsworth/Cengage Learning.

Tufte, E. R. (1990). Envisioning information. Cheshire, UK: Graphic Press.

Tufte, E. R. (2001). The visual display of quantitative information (2nd ed.). Cheshire, UK: Graphic Press. 